\title{
Parallel Heat-Exchangers Network Optimization Using Sliding Mode Extremum Seeking with integral Anti Wind Up Scheme
}

\author{
Taha Adel Al-Gadery ${ }^{1}$, Shibly Ahmed Al-Samarraie ${ }^{2}$ \\ ${ }^{12}$ Control \& System Engineering Dept, University of Technology, Baghdad, Iraq. \\ ${ }^{1}$ cse.19.06@grad.uotechnology.edu.iq, ${ }^{2} 60132 @$ uotechnology.edu.iq.
}

\begin{abstract}
In this paper, we study the Sliding Mode Extremum Seeking (SMES) optimization method for a Heat Exchangers Network. The studied network is constructed from plate Heat Exchangers, in which several thermal sources are used to heat a common cold stream that is distributed between the several branches of the network. The considered optimization problem is the optimization of the thermal power gained from different hot sources. The control variables are the split ratios of the cold stream to the different heat exchangers. The dynamical model for general Heat Exchanger Network with (n) Heat Exchangers was driven and the special case of two Heat Exchangers in parallel was considered as a case study. The SMES algorithm was modified with an integral anti-windup scheme to constrain the search within the admissible region. The simulation results obtained by using Matlab program confirmed the effectiveness of the approach.
\end{abstract}

Index Terms - Heat Exchangers Network, Sliding Mode Based Extremum Seeking, Real-time Optimization.

\section{INTRODUCTION}

Heat Exchanger is a very important piece of equipment in process industries where it is used to transfer heat between two or more fluids for either heating or cooling processes [1]. They are often arranged in networks to distribute the available hot streams effectively [2].

Nowadays, with the increasing interest in energy conservation, the efficient use of HE's network can be a useful tool for energy conservation, especially in the heat recovery process from different parts of a process [3].

The optimal operation of the HE's networks is not as popular as the optimal design. The work in [4] was one of the firsts to discuss the optimal operation of heat exchangers network in which simultaneous regulation and optimization are considered. In 1994, another approach was proposed by minimizing utility consumption [5] and in 2012, a selfoptimizing approach was introduced in which the split ratio of the cold stream to the different branches is considered as the only manipulated variable [6]. In 2014, differential evolution with stream splitting was used for HE network optimization [7]. And in [8], the entransy theory was used in optimizing the heat transfer in HE networks. A strong real-time optimization technique that is used to optimize a function with unknown analytical form is the Extremum Seeking (ES) [9], it is capable of dealing with optimization problems in which only the output (performance measure) are available which is the case when either the system or the cost function is unknown. The use of extremum seeking in real-time optimization dates back to 1922 in Leblanc's publication [10] but it was not until the late 1990's that the stability proves were introduced [11]. And today, there is a growing interest in this field. 
There exist several approaches for extremum seeking [9]. One of the most popular is the Perturbation Based Extremum Seeking (PBES), which uses a sinusoidal perturbation at the inputs to get an online estimation of the gradient of the output relative to the inputs, and the latter will be used to modify the inputs toward the extremum [9]. In [12]-[14], the PBES was used for HE networks and heat transfer optimization problems. In [15], Fast Fourier Transform based Extremum Seeking scheme was introduced for optimizing the operation of HE networks.

In this paper, the sliding mode based extremum seeking scheme will be used to optimize the heating utility of a parallel heat exchanger network. This approach was based on the sliding mode concepts, one of the strong nonlinear control techniques that have been used widely in observation and control [16]-[17]. The dynamical model for a general heat exchanger network with (n) heat exchangers will be derived and the special case of two heat exchangers in parallel will be used as a case study. The SMES will be used to update the split ratio to maximize the temperature of the outlet cold stream. The Matlab software will be used as the simulation environment.

The rest of the paper is organized as follows: In Section II, the mathematical modelling of the general parallel heat exchangers network was driven. In Section III, the statement of the optimization objective and the cost function were introduced. In Section IV, The SMES optimization method was analyzed. The specification of the admissible search region and a modification for the SMES algorithm to constrain the search in this region was proposed in Section V. Section VI shows the simulation results obtained with the MATLAB simulation environment for the special case of two heat exchangers in parallel. Finally, conclusions are included in the last section.

\section{SYSTEM DESCRIPTION AND MODELING}

In this paper, we will consider the heat exchangers network configuration shown in Fig. 1 in which (n) number of the heat exchanger is connected in parallel.

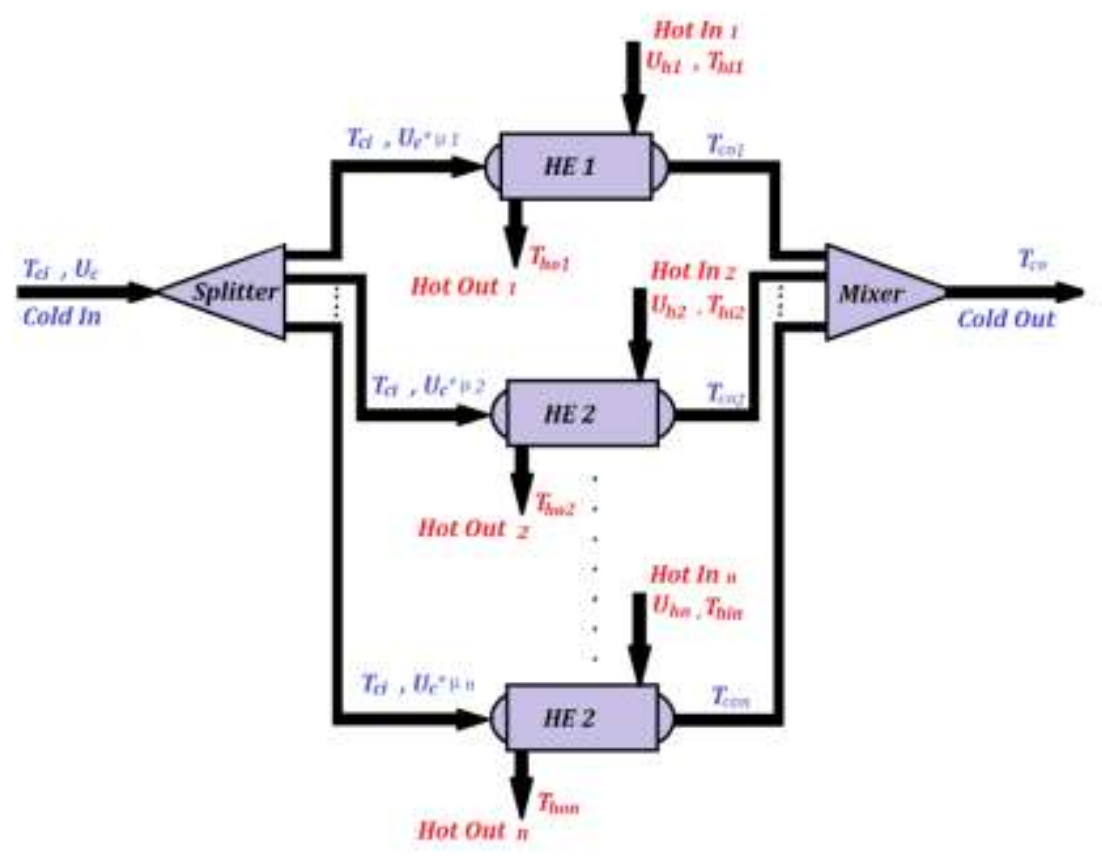

Fig. 1. PARALlEL HEAT EXCHANGER NETWORK 
The volumetric flow rate $\left(U_{c}\right)$ of common feed (Cold In) is considered constant and is distributed among the different heat exchangers (HE) by the splitter, where $\mu_{1}, \mu_{2}, \ldots \mu_{n}$ are the split ratios such that:

$$
\sum_{i=1}^{n} \mu_{i}=1
$$

Each heat exchanger is a plate heat exchanger [18]. The temperature of the input cold stream $\left(T_{c i}\right)$ is the same for each heat exchanger, while the input hot streams may have different temperatures $\left(T_{h i 1}, T_{h i 2}, \ldots, T_{h i n}\right)$ and volumetric flow rates $\left(U_{h 1}, U_{h 2}, \ldots, U_{h n}\right)$ for each heat exchanger.

For the heat exchanger (i) and under the following assumptions:

1- The heat transfer coefficients are constant.

2- The hot and cold streams are single-phase ideal fluids

3- Density $(\rho)$ and specific heat $\left(C_{p}\right)$ for all the streams are constant.

4- No heat transfer with the environment through the walls.

And with the temperatures of the outlet hot $\left(T_{h o i}\right)$ and cold $\left(T_{c o i}\right)$ streams as the states, the differential equations that describe the dynamics of the heat exchanger (i) is given by [18], [19]:

$$
\left.\begin{array}{c}
\dot{T}_{c o i}(t)=-k_{1 i}\left(T_{c o i}(t)-T_{h o i}(t)\right) \\
+\frac{U_{c} * \mu_{i}}{V_{c}}\left(T_{c i}(t)-T_{c o i}(t)\right) \\
\dot{T}_{h o i}(t)=-k_{2 i}\left(T_{h o i}(t)-T_{c o i}(t)\right) \\
+\frac{U_{h i}}{V_{h}}\left(T_{h i i}(t)-T_{h o i}(t)\right)
\end{array}\right\}
$$

Where;

$k_{1 i}=U_{i} A_{i} /\left(C_{p, c} \rho_{c} V_{c}\right), k_{2 i}=U_{i} A_{i} /\left(C_{p, h i} \rho_{h i} V_{h}\right), A_{i}$ is the area of the plat for the i'th HE, $U_{i}$ is the heat-transfer coefficient, $C_{p, h i}$ and $C_{p, c}$ are the hot and cold streams heat capacities respectively and $\rho_{c}$ and $\rho_{h i}$ are the densities for the cold and hot streams respectively.

It was used heat exchangers with the dynamical equations in (2), then the dynamics of the complete network in Fig. 1 can be represented in matrix form as follows:

$$
\left[\begin{array}{c}
\dot{x_{1}} \\
\dot{x_{2}} \\
\cdot \\
\dot{\dot{x_{n}}} \\
\dot{x_{n+1}} \\
\dot{x_{n+2}} \\
\cdot \\
\dot{\dot{x}_{2 n}}
\end{array}\right]=\left[\begin{array}{c}
-k_{11}\left(x_{1}(t)-x_{n+1}(t)\right) \\
-k_{12}\left(x_{2}(t)-x_{n+2}(t)\right) \\
\cdot \\
\cdot \\
-k_{1 n}\left(x_{n}(t)-x_{2 n}(t)\right) \\
-k_{21}\left(x_{n+1}(t)-x_{1}(t)\right)+\frac{U_{h 1}}{V_{h}}\left(T_{h i 1}(t)-x_{n+1}(t)\right) \\
-k_{22}\left(x_{n+2}(t)-x_{2}(t)\right)+\frac{U_{h 2}}{V_{h}}\left(T_{h i 2}(t)-x_{n+2}(t)\right) \\
\cdot \\
\cdot \\
-k_{2 n}\left(x_{2 n}(t)-x_{n}(t)\right)+\frac{U_{h n}}{V_{h}}\left(T_{h i n}(t)-x_{n}(t)\right)
\end{array}\right]+G(x)\left[\begin{array}{c}
u_{1} \\
u_{2} \\
\cdot \\
\cdot \\
u_{n} \\
0 \\
0 \\
\cdot \\
\cdot \\
0
\end{array}\right]
$$

and the temperature of the total outlet cold stream $\left(T_{c o}\right)$ can be calculated as [20]:

$$
T_{c o}=\sum_{i=1}^{n} T_{c o i} * \mu_{i}=\sum_{i=1}^{n} x_{i} * u_{i}
$$


Where;

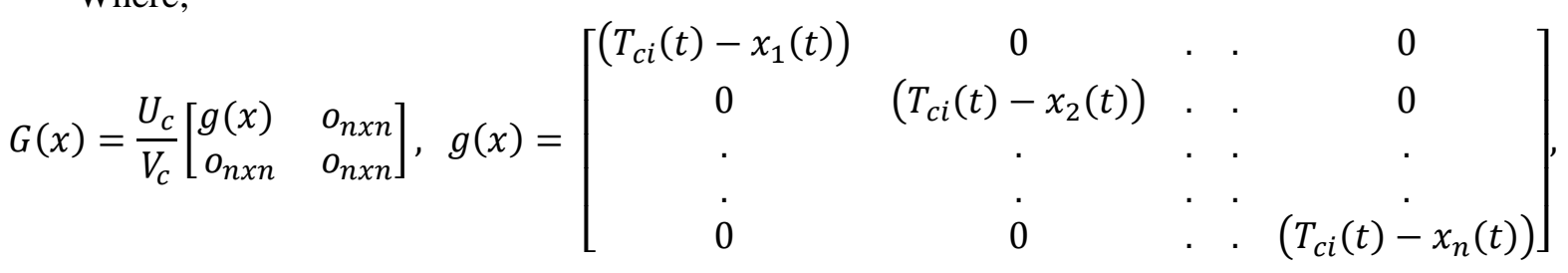
$\left[\begin{array}{c}x_{1} \\ x_{2} \\ \cdot \\ \cdot \\ x_{n}\end{array}\right]=\left[\begin{array}{c}T_{c o 1} \\ T_{c o 2} \\ \cdot \\ \cdot \\ T_{c o n}\end{array}\right]$ and,$\left[\begin{array}{c}x_{n+1} \\ x_{n+2} \\ \cdot \\ \cdot \\ x_{2 n}\end{array}\right]=\left[\begin{array}{c}T_{h o 1} \\ T_{h o 2} \\ \cdot \\ \cdot \\ T_{h o n}\end{array}\right]$ are the states. And $\left[\begin{array}{c}u_{1} \\ u_{2} \\ \cdot \\ \cdot \\ u_{n}\end{array}\right]=\left[\begin{array}{c}\mu_{1} \\ \mu_{2} \\ \cdot \\ \cdot \\ \mu_{n}\end{array}\right]$ are the control inputs, with $\sum_{i=1}^{n} u_{i}=1$.

\section{THE OPTIMIZATION PROBLEM}

The optimization problem considered in this paper is to optimize the heating utility by maximizing the thermal power $\left(P_{T}\right)$ collected from the different hot streams which can be calculated as [12]:

$$
P_{T}=\sum_{i=1}^{n} U_{c} * \mu_{i} *\left(T_{c o i}-T_{c i}\right)
$$

And since the flow and temperature of the inlet cold stream are assumed to be constant, then the optimization problem can be approximated as:

$$
J=\sum_{i=1}^{n} \mu_{i} * T_{c o i}=\sum_{i=1}^{n} u_{i} * x_{i}=T_{c o}
$$

Thus, the objective is to maximize the temperature of the total outlet cold stream by searching for the optimal values of the split ratios $\left(u_{i}\right)$.

\section{SLIDING MODE WITH EXTREMUM SEEKING OPTIMIZATION}

The block diagram for this scheme is shown in Fig. 2. The basic idea is to force the performance measure $(J)$ to follow an increasing /decreasing time function $(g(t))$ via sliding mode concepts.

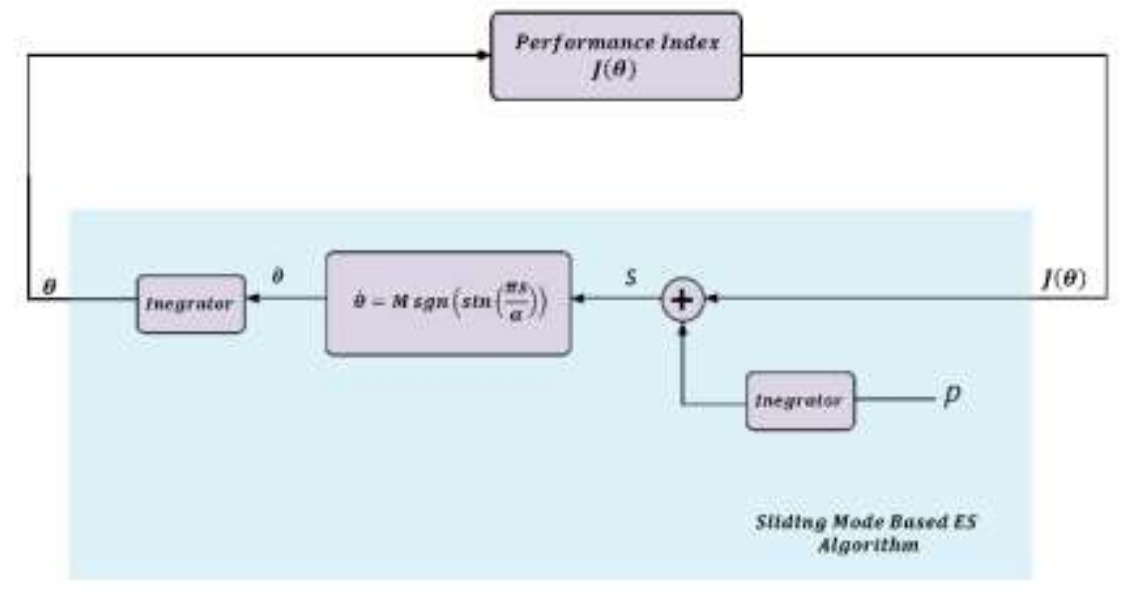

Fig. 2. Block DIAGRAM OF SLIDING MODE BASED EXTREMUM SEEKING SCHEME. 
Consider the stable nonlinear system:

$$
\dot{x}=f(x(t), \theta)
$$

with cost function:

$$
y=J(x(t))
$$

where; $x \in R^{n}$ is the state, $\theta \in R^{m}$ is a vector of the controlled variables (the split ratios $u_{i}$ for the HE network in this paper), $J \in R$ is the performance index (that is $T_{c o}$ in Eq.6 for the HE network), and the functions $f(x, \theta)$ and $J(x)$ are smooth.

In addition, we make the following assumptions [21]:

Assumption 1: For each $\theta \in R^{m}$, the equilibrium point $x=l(\theta)$ is unique and exponentially stable.

Assumption 2: There exists a unique $\theta=\theta^{*}$ such that $(J \circ l)^{\prime}\left(\theta^{*}\right)=0$ and $(J \circ l)^{\prime \prime}\left(\theta^{*}\right)>0$ for minimization problem (or $(\mathrm{J} o l)^{\prime \prime}\left(\theta^{*}\right)<0$ for maximization problem).

Now consider the sliding variable:

$$
s(t)=J(t)-g(t)
$$

with: $\dot{g}(t)=p$

$$
\rightarrow \dot{s}(t)=\dot{J}(t)-\dot{g}(t)=\left(\frac{\partial J}{\partial \theta}\right)^{T} \dot{\theta}-p
$$

where: $p \in R$ is the desired rate of change of $J(t)$ during sliding phase, $s \in R$ is the sliding variable, $g \in R, \frac{\partial J}{\partial \theta} \in R^{1 \times m}$, and $\dot{\theta} \in R^{m \times 1}$

Then by choosing:

$$
\dot{\theta}=K \cdot \operatorname{sgn}\left(\sin \left(\frac{\pi s}{\alpha}\right)\right)
$$

and according to [21-24], a sliding motion will exist in the region $\left|\frac{\partial J}{\partial \theta}\right|>\frac{p}{k}$ and $\theta$ will move toward $\theta^{*}$. Note that in (11), $K$ is a raw vector $\left(K=\left[\begin{array}{llllll}k_{1} & k_{2} & . & . & . & k_{m}\end{array}\right]\right)$ and $\operatorname{sgn}(\sin ()$.$) is a diagonal$ operator thus:

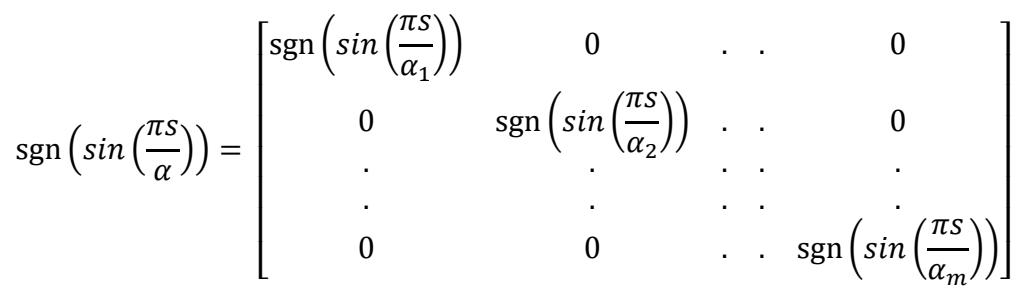

where $\alpha_{i}$ are sufficiently small positive constants.

\section{ADMISSIBLE SEARCH REGION}

For HE network with (n) number of branches, the cost function $J$ in Eq. 6 should be maximized by searching for the optimal values of split ratios $\left(u_{1}, u_{2}, \ldots, u_{n}\right)$, and since $\sum_{i=1}^{n} u_{i}=1$, then $u_{n}=1-\sum_{i=1}^{n-1} u_{i}$ and the problem is reduced to (n-1) parameter.

And since $\sum_{i=1}^{n} u_{i}=1$, the search for optimal must be constrained within this region. In this paper, a hierarchical definition of the search region boundaries for each branch was proposed in the following manner: the saturation limits of the split ratio of the first branch in the network was defined as: 


$$
\left(u_{1 l}=0\right) \leq u_{1} \leq\left(u_{1 u}=1\right)
$$

and of the second branch as:

$$
\left(u_{2 l}=0\right) \leq u_{2} \leq\left(u_{2 u}=1-u_{1}\right)
$$

and for the i'th branch:

$$
\left(u_{i l}=0\right) \leq u_{i} \leq\left(u_{i u}=1-\sum_{j=1}^{i-1} u_{j}\right)
$$

where $u_{i l}$ and $u_{i u}$ refer to the lower and upper limits of the split ratio $u_{i}$ respectively.

Thus, the value of $u_{i}$ should remain within these limits. To achieve this, the idea of integral antiwind-up [25],[26] was used to modify the algorithm as shown in Fig. 3, where:

$$
\dot{u}_{i}=k_{i} \operatorname{sgn}\left(\sin \left(\frac{\pi s}{\alpha_{i}}\right)\right)-k_{s}\left(u_{i}-S A T\left(u_{i}\right)\right)
$$

where; $k_{s}$ is a small positive constant and:

$$
\operatorname{SAT}\left(u_{i}\right)=\left\{\begin{array}{lr}
u_{i u} & u_{i} \geq u_{i u} \\
u_{i} & u_{i l}<u_{i}<u_{i u} \\
u_{i l} & u_{i} \leq u_{i l}
\end{array}\right.
$$

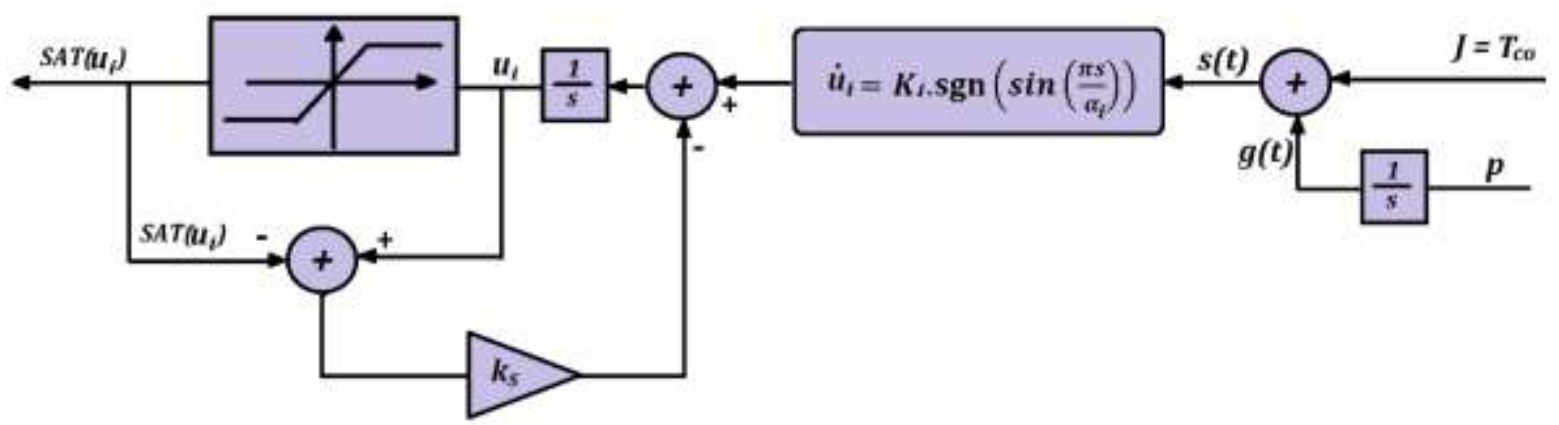

Fig. 3. The Block Diagram of SMES with InTEgRal ANTI-Windup MOdificAtion

Thus, if the SMES algorithm generated a value for $u_{i}$ below the lower limit $u_{i l}$ then the antiwind-up scheme will add a positive term to the integrator and the value of $u_{i}$ will increase back into the admissible search region, and similarly, when the value for $u_{i}$ above the upper limit $u_{i u}$ then the anti-wind-up scheme will add a negative term.

\section{SIMULATIONS AND RESULTS}

As a case study, the simple case of two heat exchangers in parallel will be considered here. The parameter values for each heat exchanger are given in Table 1 and Table 2 respectively with the volumetric flow rate and temperature of the main cold stream given by $U_{c}=150 \mathrm{~cm}^{3} / \mathrm{min}$ and $T_{c i}=20 \mathrm{Co}^{\circ}$. And since we only have two branches, then $u_{2}$ can be represented in terms of $u_{1}$ :

Let $u_{1}=u \rightarrow u_{2}=1-u$, then the problem is reduced to a single parameter optimization problem. 
TABLE 1. Nominal Parameters Values of HE 1

\begin{tabular}{cccc}
\hline \hline parameter & Nominal value & parameter & Nominal value \\
$A_{1}$ & $0.0672 \mathrm{~m}^{2}$ & $U_{h 1}$ & $150 \mathrm{~cm}^{3} / \mathrm{min}$ \\
$C_{p, c}$ & $4180 \mathrm{~J} / \mathrm{kg} \cdot \mathrm{C}^{o}$ & $V_{c}$ & $5.3710^{-4}$ \\
$C_{p, h 1}$ & $4180 \mathrm{~J} / \mathrm{kg} \cdot C^{o}$ & $V_{h}$ & $5.3710^{-4}$ \\
$U_{1}$ & $300 \mathrm{~W} / \mathrm{m}^{2} \mathrm{C}^{o}$ & $T_{h i 1}$ & $80 \mathrm{C}^{o}$ \\
$\rho_{h 1}$ & $1000 \mathrm{~kg} / \mathrm{m}^{3}$ & $\rho_{c}$ & $1000 \mathrm{~kg} / \mathrm{m}^{3}$ \\
\hline \hline
\end{tabular}

TABLE 2. Nominal Parameters Values of HE 2

\begin{tabular}{cccc}
\hline \hline parameter & Nominal value & parameter & Nominal value \\
$A_{2}$ & $0.0672 \mathrm{~m}^{2}$ & $U_{h 2}$ & $120 \mathrm{~cm}^{3} / \mathrm{min}$ \\
$C_{p, c}$ & $4180 \mathrm{~J} / \mathrm{kg} \cdot \mathrm{C}^{o}$ & $V_{c}$ & $5.3710^{-4}$ \\
$C_{p, h 2}$ & $4180 \mathrm{~J} / \mathrm{kg} \cdot \mathrm{C}^{o}$ & $V_{h}$ & $5.3710^{-4}$ \\
$U_{2}$ & $300 \mathrm{~W} / \mathrm{m}^{2} \mathrm{C}^{o}$ & $T_{h i 1}$ & $95 \mathrm{C}^{o}$ \\
$\rho_{h 2}$ & $1000 \mathrm{~kg} / \mathrm{m}^{3}$ & $\rho_{c}$ & $1000 \mathrm{~kg} / \mathrm{m}^{3}$ \\
\hline \hline
\end{tabular}

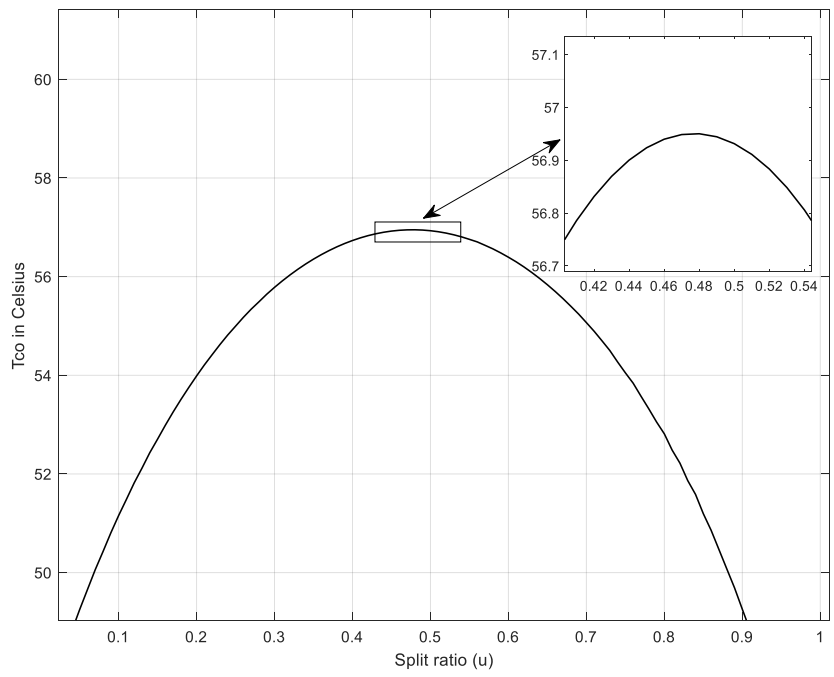

Fig. 4. The Steady State Map $\left(\mathbf{u} \rightarrow \mathbf{T}_{\mathbf{c o}}\right)$

The steady-state map $\left(u \rightarrow T_{c o}\right)$ for the network is shown in Fig. 4. From this figure, it can be seen that the system is open-loop stable for all $u \in[0,1]$ and $T_{c o}$ has a global maximum of $T_{c o}=56.95 \mathrm{C}^{\circ}$ at $u=0.48$ which agrees with assumptions 1 and 2 thus we should expect a similar result from the SMES algorithm.

Remark: In all simulations, the dynamic of the control valve was approximated as a first-order delay with unity gain $\left(\frac{1}{S+1}\right)$.

Next, we will implement the SMES on the model. The design parameters for the SMES were selected according to [22] and are given in Table. 3. By selecting $(k=0.001)$ and $(p=0.01), J(u)$ will converge to a close neighbourhood of its optimal defined by $\left(\left|\frac{\partial J}{\partial u}\right| \leq \frac{p}{k}=10\right)$ or equivalently $(J(u) \geq 56.4)$ as demonstrated in Fig. 5. 


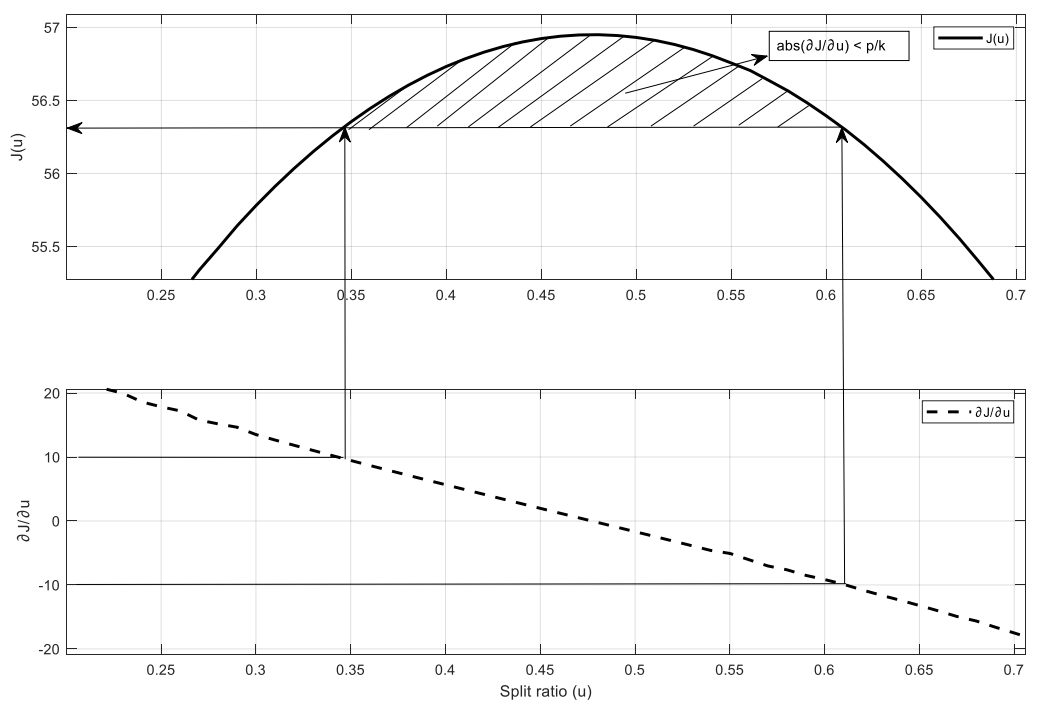

Fig. 5. Demonstrating the Correlation Between the Bounds on $\left|\frac{\partial J}{\partial u}\right|$ AND $\boldsymbol{J}(\boldsymbol{u})$

\section{TABLE 3. DESIGN PARAMETERS FOR THE SMES ALGORITHM}

\begin{tabular}{cc}
\hline \hline parameter & value \\
$\alpha$ & 0.5 \\
$k$ & 0.001 \\
$p$ & 0.01 \\
\hline \hline
\end{tabular}

The specification of the third parameter $(\alpha)$ is governed by the necessary condition for stability of the algorithm [23] ( $\alpha \geq 2 \tau p)$ where $\tau$ is the time delay of the system, defined as the time from the instant $\dot{u}$ changes (from $( \pm k)$ to $(\mp k)$ ) at $\left(t_{1}\right)$ to the instant $(J(u))$ reaches its next peak value $\left(t_{2}\right)$, and it was obtained to be less than 2 seconds as shown in Fig. 6 , thus choosing ( $\alpha=0.5$ ) should be sufficient.
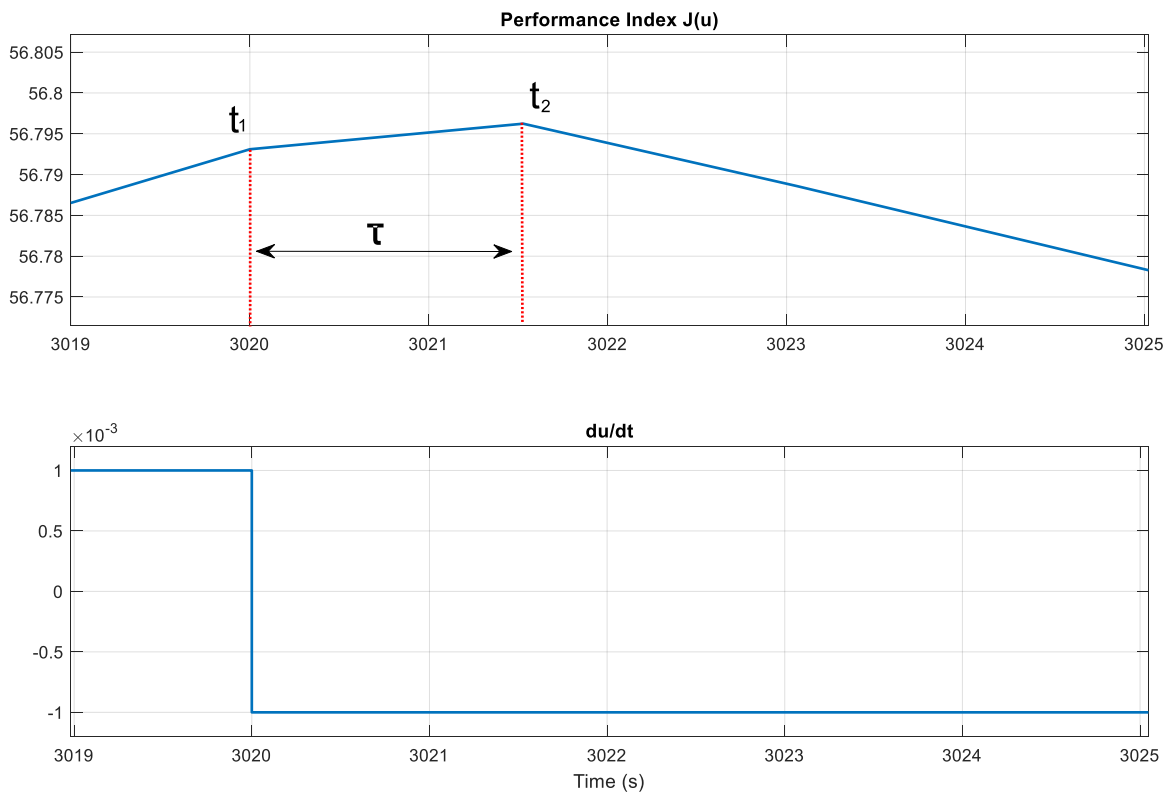

Fig. 6. Evaluation of the Delay Time $(\boldsymbol{\tau})$ 
Another important factor to consider in selecting the design parameters is the magnitude of the sustained oscillation $(M)$ in $u$ governed by [22]:

$$
M=\int_{0}^{a / p} k d t=\frac{\alpha * k}{p}
$$

From the condition above, the need for a compromise between the ultimate bound on $J(u)$ and the magnitude of the sustained oscillation $M$ can be observed, choosing larger $k$ will reduce this ultimate bound but at the expense of larger $M$.

Figure 7 shows the block diagram of the overall system (the HE network with the modified SLES algorithm), the controlled variable is the split ratio $u$.

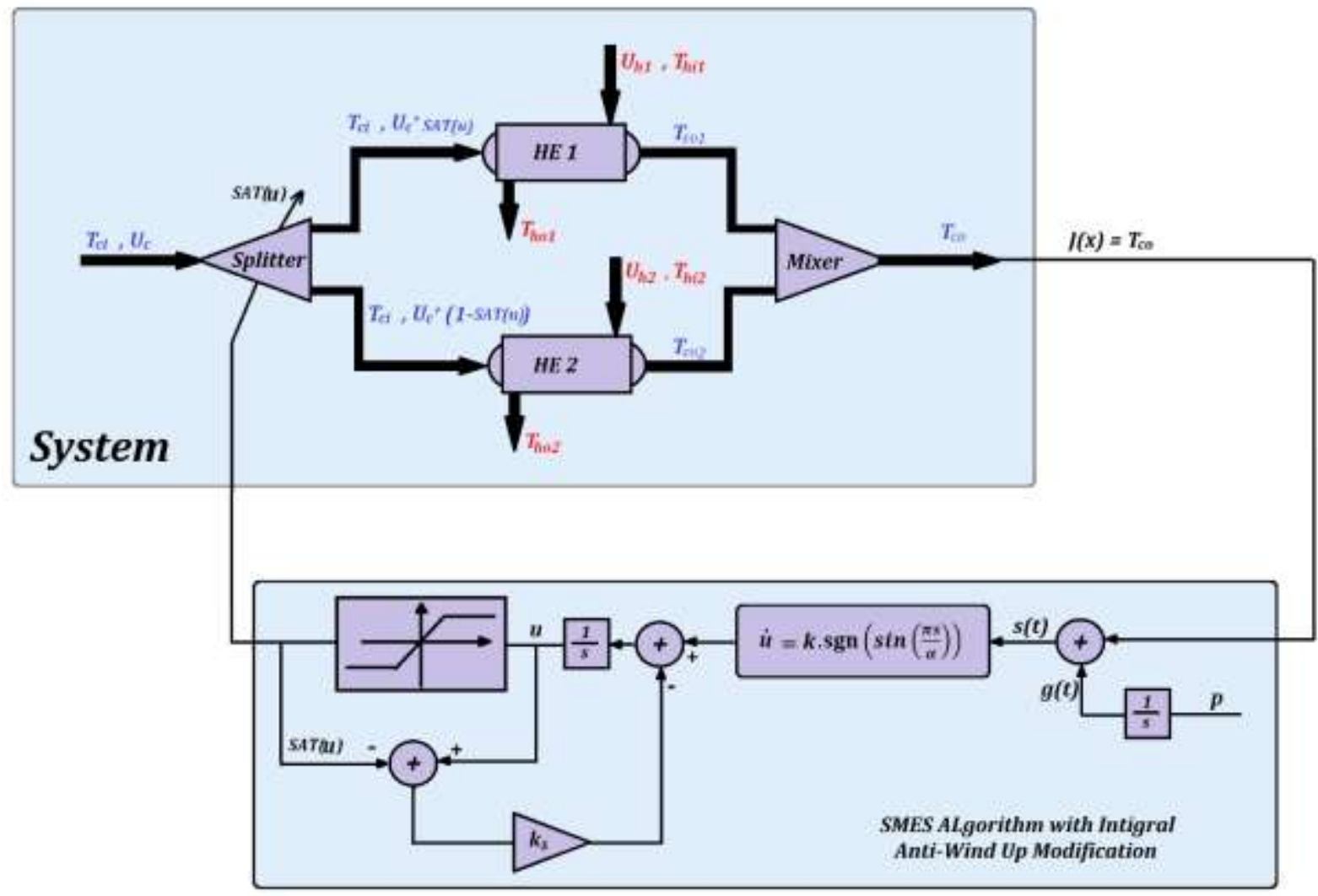

FIG. 7. BLOCK DIAGRAM OF THE OVERALL SYSTEM

The simulation results for the HE network with the parameters in Table 1 and Table 2 and with SMES design parameter in Table 3 are shown in Figs. 8 and 9. Figure 8 shows the performance measure (the temperature of the total outlet cold stream), from which we can see that it reaches a close vicinity of its optimal value within less than $800 \mathrm{sec}$. and from the time response of the sliding variable $(s)$, it can be observed that the sliding manifold is reached within $150 \mathrm{sec}$, , then the system enters sliding motion in which $\dot{s}=0$ and $J(t)$ follows $g(t)$ while moving toward its optimal value. After that, at about $800 \mathrm{sec}$, the sliding mode existing condition is lost and the system starts to oscillate near the optimal value which is also clear from the time response of the split ratio $u$ that shows a sustained oscillation. It can be seen that the magnitude of the sustained oscillation in $u$ is about 0.05 which agrees with Eq. 15. Figure 9 shows the time responses of the four states of the network, the hot and cold outlet streams from the two HE's. 

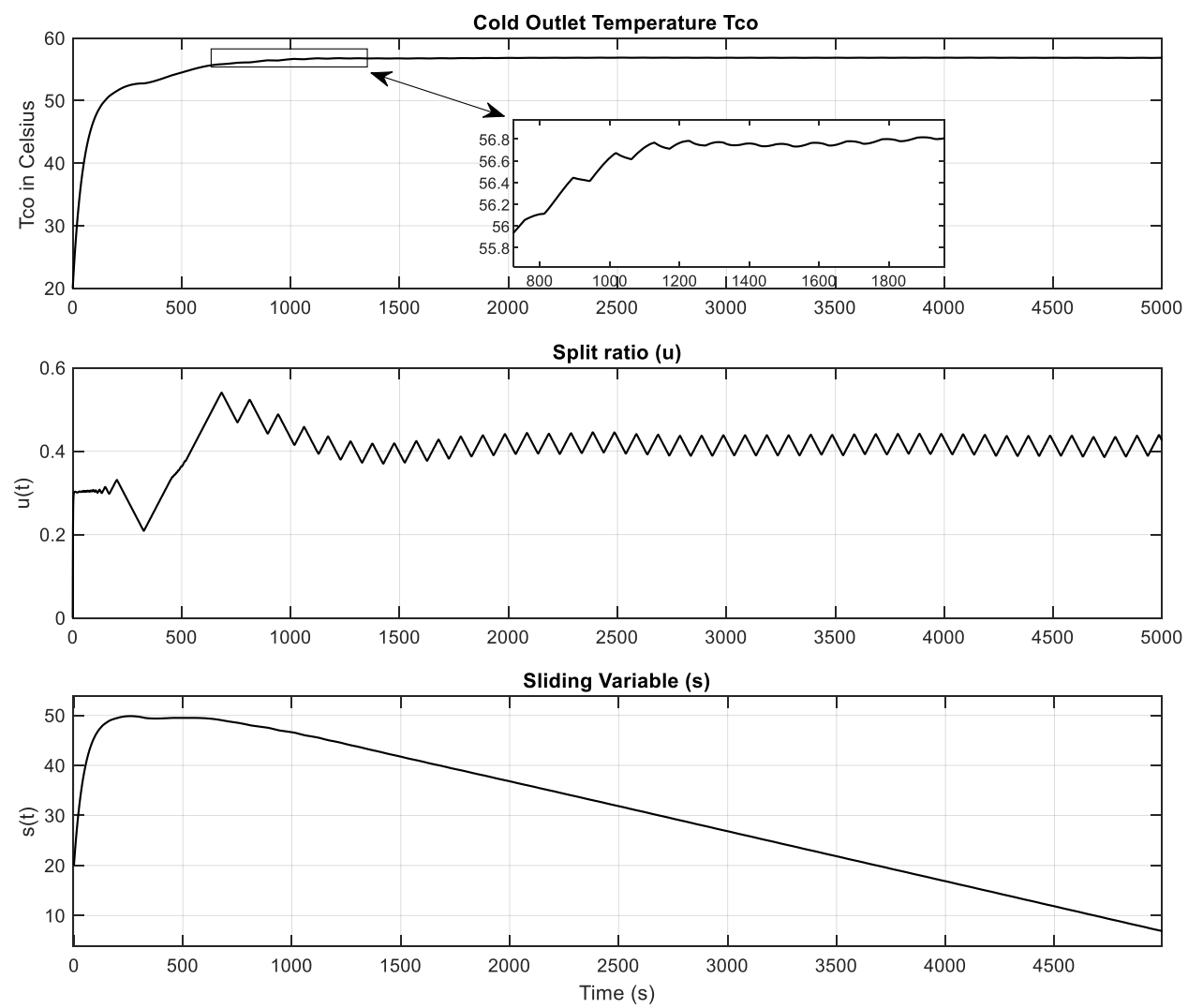

Fig. 8. The Evolution of the outlet temperature $\left(\boldsymbol{T}_{\boldsymbol{c o}}\right)$, the Split Ratio $(U)$, And the Sliding Variable $(s)$ With Time
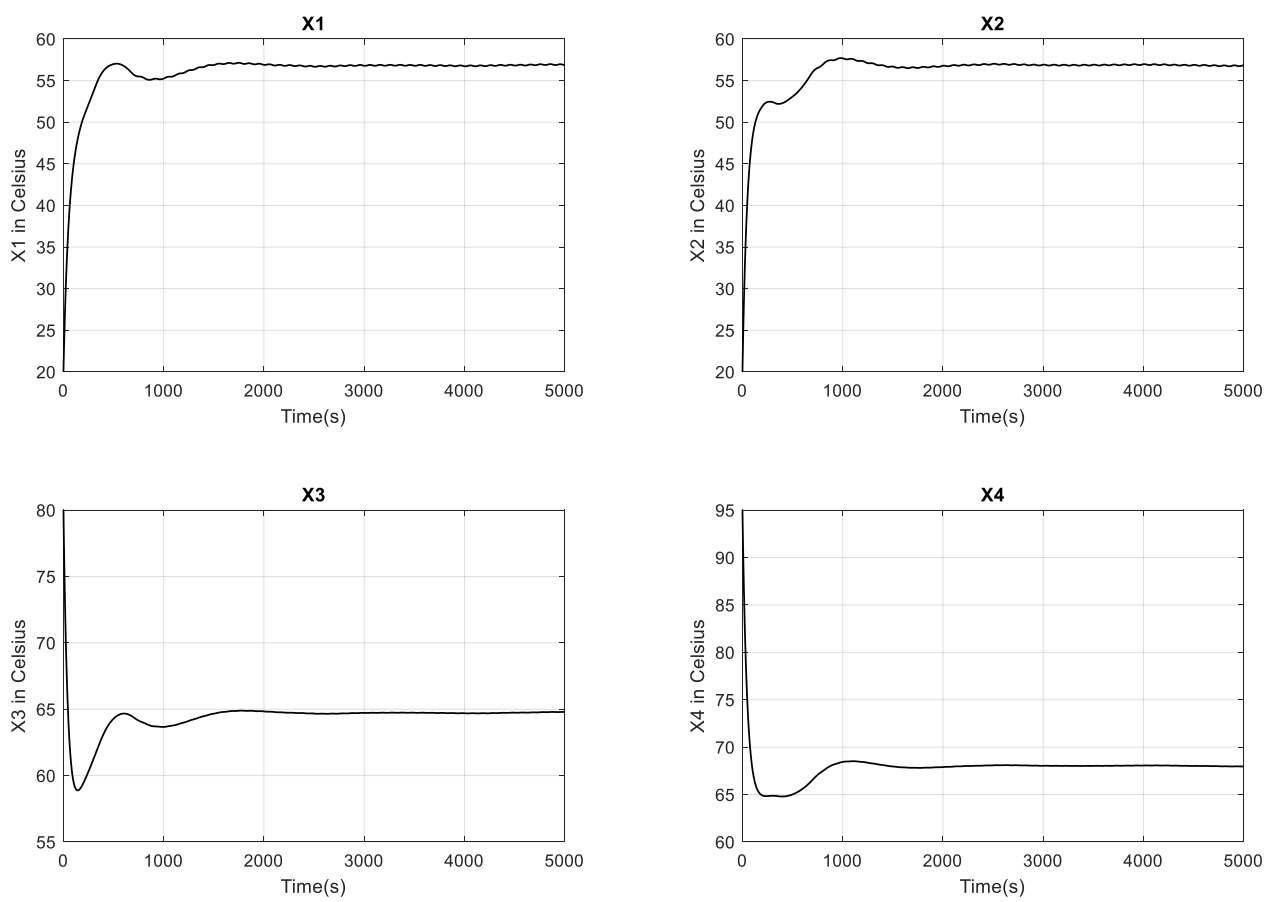

Fig. 9. The Evolution of THE FOUR STATES OF THE NETWORK With TimE 
Next, we consider the scenario in which the network parameters (or operating conditions) changes from that in Table I and Table II to the new values in Table 4 and Table 5 with $U_{c}=$ $180 \mathrm{~cm}^{3} / \min$ and $T_{c i}=20 \mathrm{C}^{\circ}$ at about $2500 \mathrm{sec}$.

TABLE 4. Nominal Parameters Values of HE 1

\begin{tabular}{cccc}
\hline \hline parameter & Nominal value & parameter & Nominal value \\
$A_{1}$ & $0.0672 \mathrm{~m}^{2}$ & $U_{h 1}$ & $170 \mathrm{~cm}^{3} / \mathrm{min}$ \\
$C_{p, c}$ & $4180 \mathrm{~J} / \mathrm{kg} . C^{o}$ & $V_{c}$ & $5.3710^{-4}$ \\
$C_{p, h 1}$ & $4180 \mathrm{~J} / \mathrm{kg} . C^{o}$ & $V_{h}$ & $5.3710^{-4}$ \\
$U_{1}$ & $300 \mathrm{~W} / \mathrm{m}^{2} \mathrm{C}^{o}$ & $T_{h i 1}$ & $70 \mathrm{C}^{o}$ \\
$\rho_{h 1}$ & $1000 \mathrm{~kg} / \mathrm{m}^{3}$ & $\rho_{c}$ & $1000 \mathrm{~kg} / \mathrm{m}^{3}$ \\
\hline \hline
\end{tabular}

TABLE 5. Nominal Parameters Values of HE 2

\begin{tabular}{cccc}
\hline \hline parameter & Nominal value & parameter & Nominal value \\
$A_{2}$ & $0.0672 \mathrm{~m}^{2}$ & $U_{h 2}$ & $160 \mathrm{~cm}^{3} / \mathrm{min}$ \\
$C_{p, c}$ & $4180 \mathrm{~J} / \mathrm{kg} \cdot C^{o}$ & $V_{c}$ & $5.3710^{-4}$ \\
$C_{p, h 2}$ & $4180 \mathrm{~J} / \mathrm{kg} \cdot C^{o}$ & $V_{h}$ & $5.3710^{-4}$ \\
$U_{2}$ & $300 \mathrm{~W} / \mathrm{m}^{2} \mathrm{C}^{o}$ & $T_{h i 1}$ & $85 \mathrm{C}^{o}$ \\
$\rho_{h 2}$ & $1000 \mathrm{~kg} / \mathrm{m}^{3}$ & $\rho_{c}$ & $1000 \mathrm{~kg} / \mathrm{m}^{3}$ \\
\hline \hline
\end{tabular}

Figure 10 shows the steady-state map $\left(u \rightarrow T_{c o}\right)$ for the new parameters and from which it can be seen that the optimal values for $\left(T_{c o}\right)$ and $(u)$ have been shifted from $T_{c o}=56.95 \mathrm{C}^{\circ}$ at $\mu=0.48$ to $T_{c o}=51.2 \mathrm{C}^{\circ}$ at $u=0.43$ respectively.

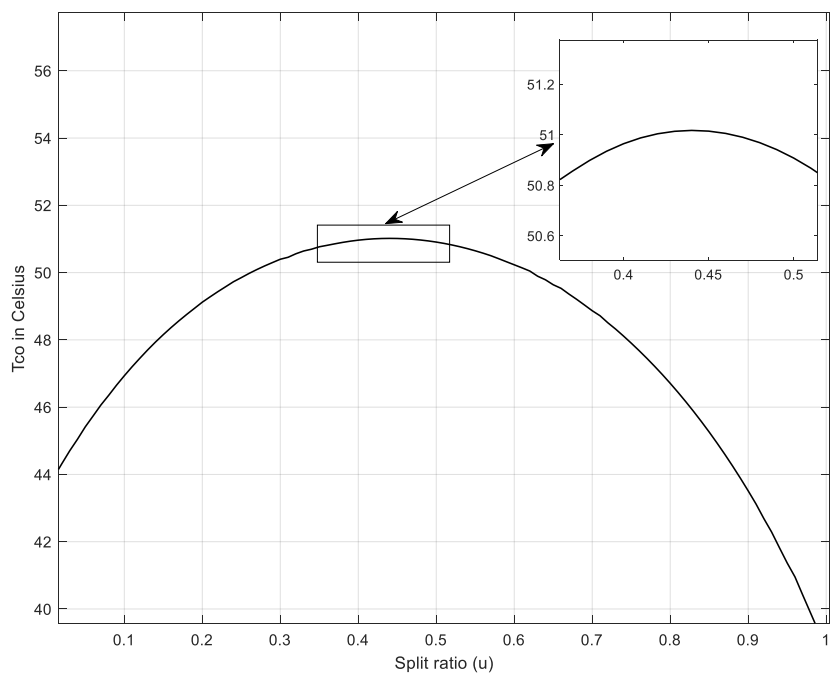

Fig. 10. The Steady State MAP $\left(\mathbf{u} \rightarrow \mathbf{T}_{\mathbf{c o}}\right)$ With THE NEW Parameters IN TABle IV AND TABle $V$

By implementing the SMES algorithm with the same design parameters in Table 3, the simulation results were obtained and are shown in Figs. 11 and 12, from which it can be seen that the SMES forced the system to track the new optimal point automatically and the system converged to close vicinity of the new optimal point relatively fast. 

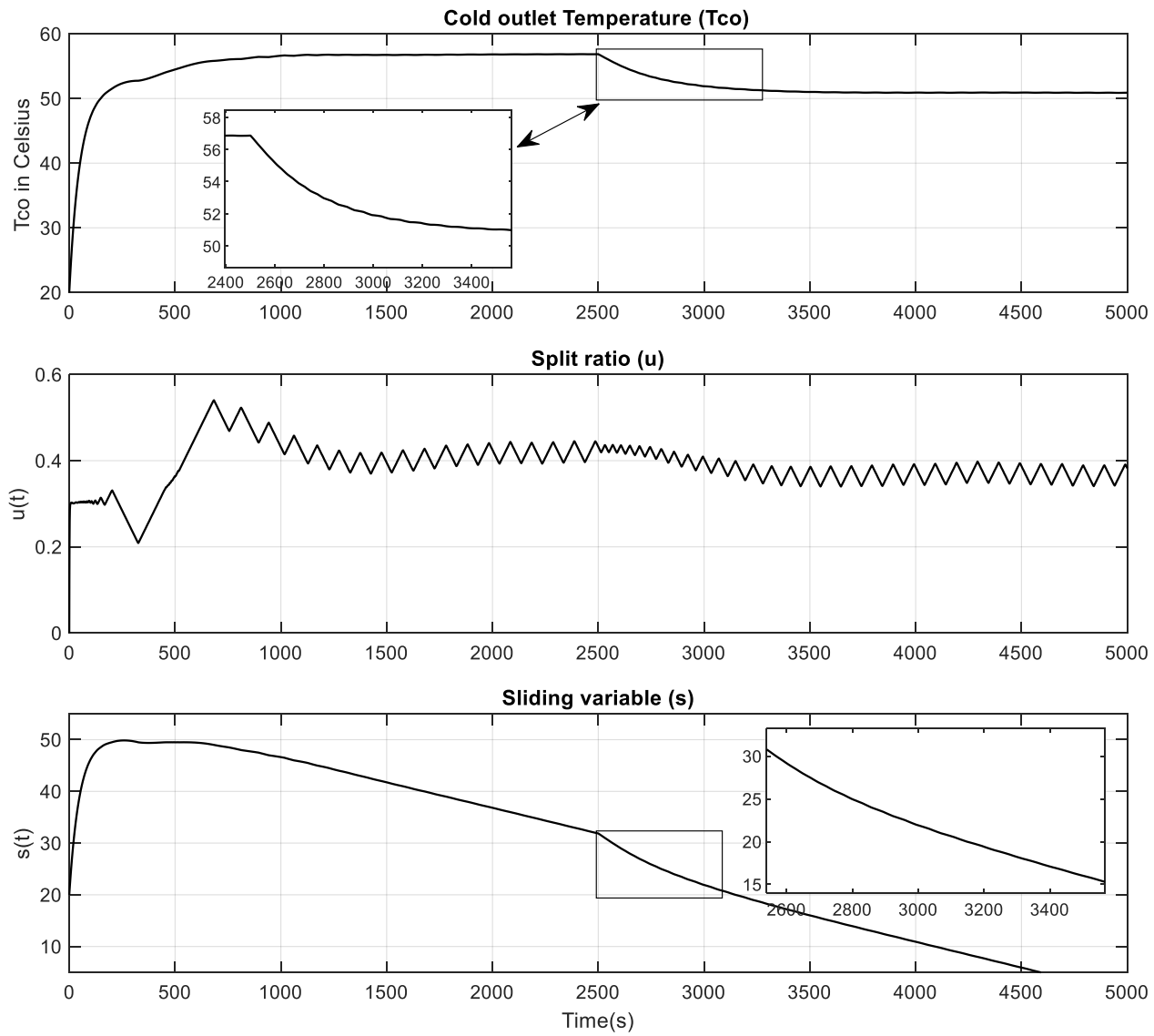

Fig. 11. The Evolution of the outlet temperature $\left(\boldsymbol{T}_{\boldsymbol{c o}}\right)$, the Split Ratio $(U)$, and the Sliding Variable $(S)$ With TIME
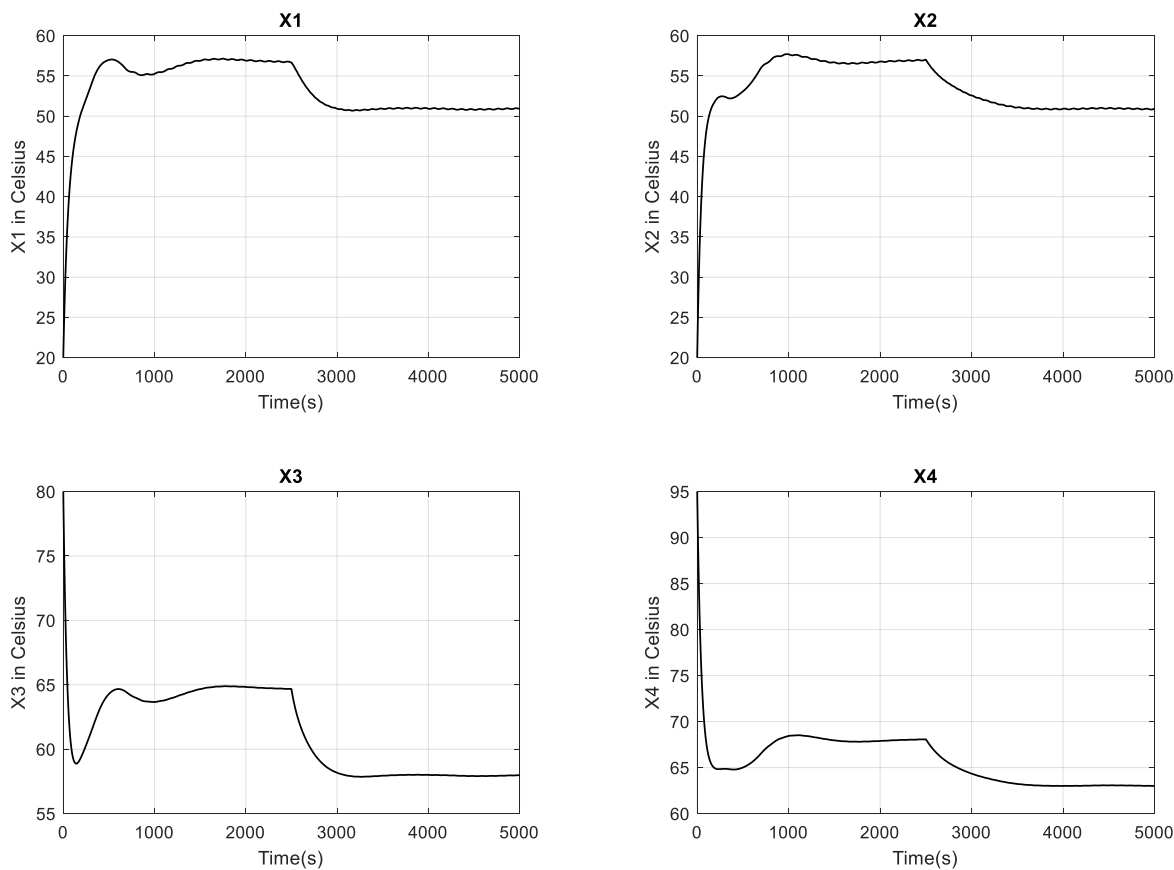

Fig. 12. THE EVOLUTION OF THE FOUR STATES OF THE NETWORK With TIME 
Finally, we will consider the case of a sudden failure in one of the branches of the network. We will assume a sudden drop in the volumetric flow rate of the hot stream to HE 2 to $0 \mathrm{~cm}^{3} / \mathrm{min}$ after 2500 seconds. With 0.3 as the initial value for the split ratio. Since there is only two branches, the new optimal point would be at $u=1$, which was calculated as $T_{c o}=43.835 \mathrm{C}^{\circ}$.

Figure 13 shows the simulation results for this case, from which it can be seen that the SMES algorithm forces the system to the new optimal point by redirecting the entire inlet cold stream to HE $1(u=1)$.
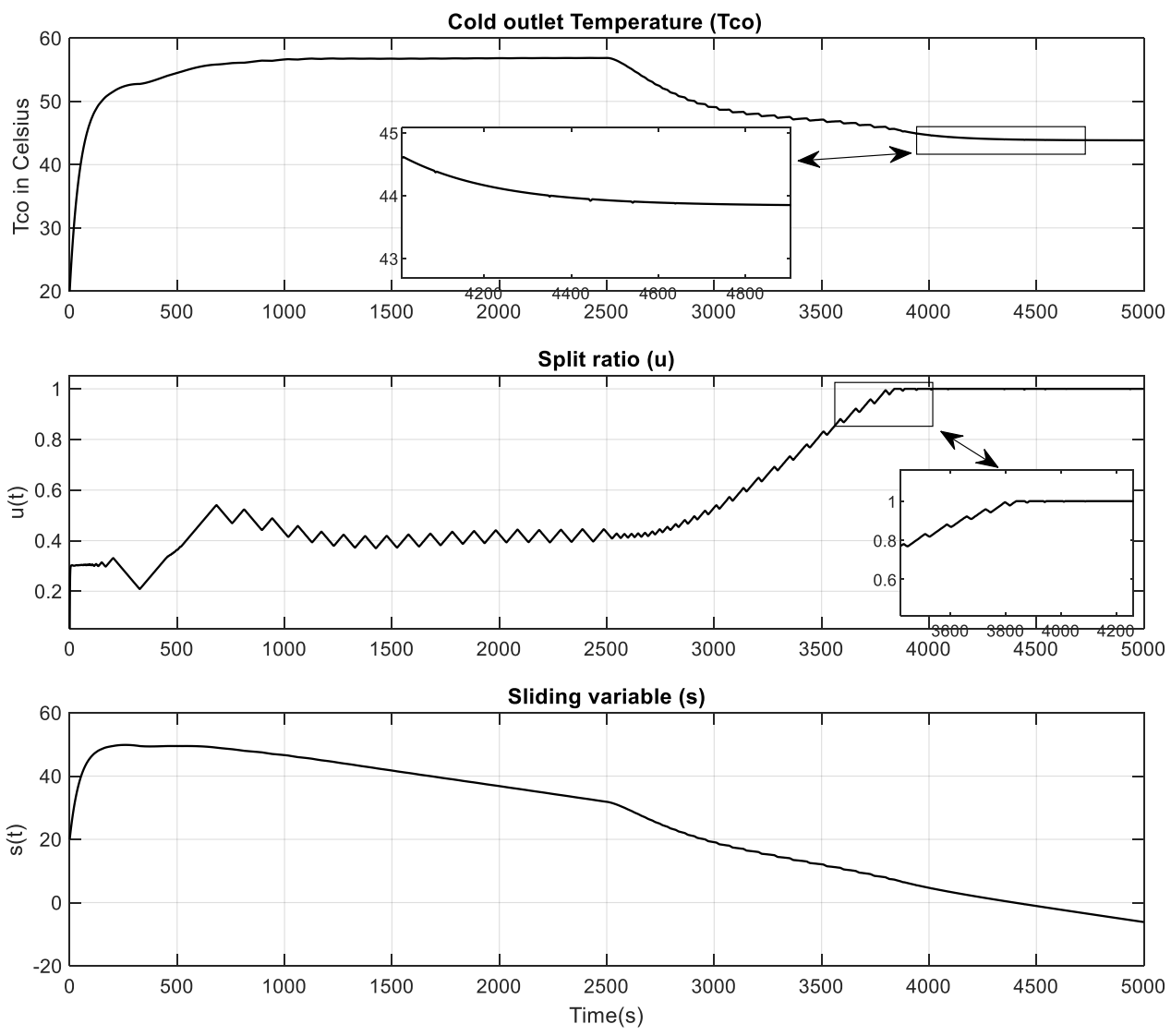

Fig. 13. The Evolution of the outlet temperature ( $\left.\boldsymbol{T}_{\boldsymbol{c o}}\right)$, the Split Ratio $(U)$, and the Sliding Variable $(S)$ With TIME FOR THE CASE OF SUDDEN FAILURE

\section{CONCLUSION}

In this paper, we implemented the Sliding Mode-based Extremum Seeking optimization method with periodic switching function to solve the heating utility optimization problem for parallel heat exchanger network. The dynamical model for the general heat exchangers network with (n) heat exchanger was derived and the special case of two heat exchangers in parallel was considered as a case study.

The main optical for this system was the physical constraints on input (split ratio) which required a modification for the original SMES algorithm. In section V, a modification for the algorithm was proposed to solve this problem. The admissible search Region for the split ratio of each network branch was defined hierarchically and the SMES was modified with an anti-windup scheme to constrain the search in these regions. The Matlab software was used as the simulation environment to demonstrate the effectiveness of the proposed approach. The simulation results obtained for the three different scenarios showed that the modified SMES provided an efficient approach for real-time 
optimization of the heating utility. In all the cases, the cold outled temperature converged to a small neighbourhood around its maximum value. A sustained oscillation with a relatively large magnitude appeared in the time response of the split variable, and since it is the direct-controlled variable in addition to the fact that in practice the split control is achieved by control valves, thus, it might be impractical to demand a high rate of split ratio change. Therefore, it's recommended for future works to further filter the spite variables and focuse on dampening the magnitude of the oscillation without affecting the convergence speed.

\section{REFERENCES}

[1] Ahmed T. Al-Sammarraie, Kambiz Vafai, "Heat transfer augmentation through convergence angles in a pipe," Numerical Heat Transfer, Part A: Applications, Vol. 72, No 3, pp. 197-214, Sep., 2017.

[2] R. Sinnott, G. Towler, “Chemical Engineering Design,” Butterworth-Heinemann, 5th ed., London, 2009.

[3] D. Zhang, Y. Yang, M. Pan, Z. Gao, “Toward a heat recovery chimney,” Sustainability, Vol. 3, No 11, pp. 2115-2128, Nov., 2011.

[4] D. Marselle, M. Morari, D. F. Rudd, "Design of resilient processing plants: Design and control of energy management systems," Chemical Engineering Science, Vol. 37, No 2, 1982.

[5] K. W. Mathisen, M. Morari, S. Skogestad, "Optimal operation of heat exchanger networks," Process Systems Engineering (PSE '94), Kyongju, Korea, 1994.

[6] J. Jaeschke, "Parallel Heat Exchanger Control," United Kingdom Patent Application No. 1207770.7, 2012.

[7] T. Ngo, R. Pendyala, N. Marneni, "Heat Exchanger Network Optimization Using Differential Evolution with Stream Splitting,” Applied Mechanics and Materials, Vol. 625, pp. 373-377, 2014.

[8] Zhang Xiangzhi, "The application of entransy theory in heat transfer optimization of heat exchanger networks and multi-stage latent heat storage systems," MRes thesis, University of Nottingham. 2018.

[9] K.B. Ariyur, M. Krstic, "Real-time Optimization by Extremum-seeking Control," Wiley-Interscience, Hoboken, 2003.

[10] M. Leblanc, "Sur l'electrification des chemins de fer au moyen de courants alternatifs de frequence elevee," Rev. Gen. Electr, 1922.

[11] M.Krstic, H.H.Wang, "Stability of extremum seeking feedback for general dynamic systems," Automatica, Vol. 36, No 2, pp. 595-601, 2000.

[12] B. Zitte, B. Hamroun, F. Couenne, I. Pitault, "Extremum-Seeking Based Distributed Optimization of Heat Exchangers Network," IFAC-PapersOnLine, Vol. 51, No 23, pp. 331-336, 2018.

[13] W. Wang, Y. Li, F. Cao, "Extremum seeking control for efficient operation of an air-source heat pump water heater with internal heat exchanger cycle vapor injection," International Journal of Refrigeration, Vol. 99, pp.. 153-165, 2019.

[14] B. Hu, Y. Li, B. Mu, S. Wang, J. Seem, F. Cao, "Extremum seeking control for efficient operation of hybrid ground source heat pump system,” Renewable Energy, Vol. 86, pp. 332-346, 2016.

[15] D. Krishnamoorthy, "On the Design and Analysis of Multivariable Extremum Seeking Control using Fast Fourier Transform," ArXiv, 2021.

[16] S.A. Al-Samarraie and A. Badri, "Integral Sliding Mode Control Desfor Electronic Throttle Valve system", AKhwarizmi Engineering Journal, Vol. 11, No.3, pp. 72-84, 2015.

[17] A. F. Abd and S. A. Al-Samarraie, "Integral Sliding Mode Control Based on Barrier Function for Servo Actuator with Friction,” Engineering and Technology Journal, Vol. 39, Part A, No. 02, pp. 248-259, 2021.

[18] N. B. Almutairi, and M, Zribi, "Control of a Plate Heat Exchanger Using the Terminal Sliding Mode Technique" Industrial \& Engineering Chemistry Research, Vol. 51, pp. 4610-4623, 2012.

[19] S.A. Al-Samarrai and L. F. Ali, "Output Feedback Adaptive Sliding Mode Control Design for a Plate Heat Exchanger" Al-Nahrain Journal for Engineering Sciences, Vol. 24, pp. 549-555, 2018. 
[20] Stian Aaltvedt, "Optimal Operation of Parallel Heat Exchanger Networks," M.Sc. thesis, Department of Chemical Engineering, Norwegian University of Science and Technology, Trondheim, Norway, 2013.

[21] S. V. Drakunov, U. Özgüner, "Optimization of nonlinear system output via sliding mode approach," Proceedings of the IEEE International Workshop on Variable Structure and Lyapunov Control of Uncertain Dynamical Systems, Sheffield, UK, pp. 61-62, 1992.

[22] Hai Yu, U. Özgüner, "Extremum-Seeking Control via Sliding Mode with Periodic Search Signals," Proceedings of the 41st IEEE Conference on Decision and Control, 2002.

[23] Y. Pan, U. Özgüner, T. Acarman, "Stability and performance improvement of extremum seeking control with sliding mode," International Journal of Control, Vol. 76, No 9-10, pp. 968-985, 2003.

[24] Y. B. Salamah and Ü. Özgüner, "Sliding Mode Multivariable Extremum Seeking Control with Application to Wind Farm Power Optimization,” 2018 Annual American Control Conference (ACC), Milwaukee, WI, pp. 5321-5326, 2018.

[25] S. Tarbouriech, G. Garcia, J.M. Gomes da Silva, I. Queinnec, “An Overview of Anti-windup Techniques. In: Stability and Stabilization of Linear Systems with Saturating Actuators," Springer, London, 2011.

[26] Y. Tan, Y. P. Li and I. Mareels, "Anti-windup for Extremum Seeking," 2012 2nd Australian Control Conference, Sydney, NSW, Australia, pp. 265-270, 2012. 